\title{
Evaluation of Overactive Bladder in Male Antidepressant Users: A Prospective Study
}

\author{
Volkan Solmaz ${ }^{1}$, Sebahattin Albayrak², Arslan Tekatass ${ }^{1}$ Dürdane Aksoy ${ }^{3}$, Yusuf Gençten ${ }^{4}$, Sema İnanır ${ }^{5}$, Fikret Erdemir ${ }^{6}$ \\ ${ }^{1}$ Department of Neurology, Faculty of Medicine, Trakya University, Edirne, Turkey \\ ${ }^{2}$ Department of Urology, Faculty of Medicine, Bozok University, Yozgat, Turkey \\ ${ }^{3}$ Department of Neurology, Gaziosmanpaşa Universty Medical Faculty, Tokat, Turkey \\ ${ }^{4}$ Department of Urology, Idıl State Hospital, Konya, Turkey \\ ${ }^{5}$ Tokat Mental and Neurological Diseases Hospital, Tokat, Turkey \\ ${ }^{6}$ Department of Urology, Faculty of Medicine, Gaziosmanpaşa Universty, Tokat, Turkey
}

Purpose: In this study, we investigated overactive bladder $(\mathrm{OAB})$ functions in male patients who used antidepressant drugs (ADs) that were previously examined in female patients, based on conflicting data in literature regarding the effects of $\mathrm{AD}$ on $\mathrm{OAB}$ and the differences between male and female urinary system physiologies (anatomical and hormonal).

Methods: The study included 202 male patients (a control group of 90 healthy subjects, and an experimental group of 112 patients taking $\mathrm{ADs}$ for different disorders). All the patients completed the overactive bladder-validated 8 (OAB-V8) questionnaire, the International Consultation on Incontinence Questionnaire-Short Form (ICIQ-SF), and the Beck Depression Inventory (BDS).

Results: The OAB-V8, ICIQ-SF, and BDS scores for the antidepressant users were significantly higher than those of the control group. The highest prevalence of $\mathrm{OAB}$ symptoms was observed in patients taking venlafaxine (68.2\%), and the lowest prevalence was in patients taking sertraline $(28.0 \%)$. Moreover, the frequency of OAB between the antidepressant groups was statistically significant. The univariate logistic regression analyses showed a significant relationship between the presence of $\mathrm{OAB}$, antidepressant usage, BDS score, and the age of a patient. In the multivariate logistic regression analyses, the association between the presence of $\mathrm{OAB}$ and antidepressant usage was statistically significant.

Conclusions: The present study showed that the incidence of OAB and the severity of OAB symptoms increased in males using antidepressants for various disorders. This may have been due to unique pharmacological effects, on a molecular or individual level, of serotonin-norepinephrine reuptake inhibitors.

Keywords: Urinary Bladder, Overactive; Antidepressive Agents; Validation Studies

- Research Ethics: The study was acknowledged by the Gaziosmanpasa University local ethics committee (15-KAEK-126).

- Conflict of Interest: No potential conflict of interest relevant to this article was reported.

\section{INTRODUCTION}

The definition of overactive bladder $(\mathrm{OAB})$ by the International Continence Society (ICS) is as a complex of symptoms: "an ur- gency, with or without urge incontinence, one which is usually frequent and concurrent with nocturia, but does not occur with a urinary tract infection or other obvious pathology" [1]. OAB is particularly widespread for the elderly population, but people

Corresponding author: Volkan Solmaz (iD http://orcid.org/0000-0002-9045-2347 Department of Neurology, Trakya Universitesi, Medical Faculty, 22030, Edirne, Turkey

E-mail: solmaz.volkan85@gmail.com / Tel: +90-284-2357641 / Fax:+90-284-2352730

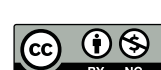

This is an Open Access article distributed under the terms of the Creative Commons Attribution Non-Commercial License (http://creativecommons.org/licenses/by-nc/4.0/) which permits unrestricted non-commercial use, distribution, and reproduction in any medium, provided the original work is properly cited. 
of all ages are affected [2]. The prevalence of OAB symptoms was reported as "sometimes to often" for $27.2 \%$ of all males and $43.1 \%$ of all females; similarly, it was reported as "often to very/ extremely frequently" at $15.8 \%$ and $32.6 \%$, for males and females, respectively [3]. The pathophysiology of these symptoms is still open to debate and is the subject of ongoing scientific research. The ICS has classified the putative underlying pathological mechanisms into 2 types: increased afferent activity and abnormal control of afferent signals [4].

Currently, cases of depression are commonly treated in primary care settings. Antidepressant (AD) medication is a useful treatment for patients with anxiety disorders and headaches, and is an effective method for the prevention of relapse and recurrence of depression [5,6]. Antidepressants are frequently prescribed in the United States, and in the 1990s, selective serotonin reuptake inhibitors (SSRIs) became a first-line pharmacological therapy for depressive disorders, replacing tricyclic antidepressants (TCAs) [7]. Antidepressants, like SSRIs and serotonin-norepinephrine reuptake inhibitors (SNRIs), have several side-effects due to the nature of these drugs, among which are nausea, headache, gastroparesis, sleep disorders, increased appetite, and impotence [8]. Even though some antidepressants are used to treat $\mathrm{OAB}$ [9], several case reports show that certain antidepressants cause higher urinary frequency, urgency, and nocturia, and induce urgent urinary incontinence (UI) $[10,11]$.

Data regarding the effects of antidepressant drugs on $\mathrm{OAB}$ are conflicting. Additionally, differences exist between the male and female urinary system physiologies due hormones and anatomy. Therefore, in this study we investigated the $\mathrm{OAB}$ functions in male patients who used ADs previously examined in female patients [12].

\section{MATERIALS AND METHODS}

\section{Study Population}

This prospective study included 202 male patients (a control group of 90 healthy subjects, and an experimental group of 112 patients taking ADs for different disorders) who were first seen at the Gaziosmanpasa University Psychiatry and Neurology clinics. All participants were acquainted with the study design, and signed an informed consent form. The study group excluded patients with urinary tract infections (diagnosed by urine culture) that had a postvoid residual volume higher than $100 \mathrm{~mL}$, a history of neurological conditions (demyelinating diseases or other neurodegenerative diseases), suprapubic pain during urination which had lasted for more than 6 months (potential indication of interstitial cystitis), who had gone through pelvic radiotherapy or urinary system malignancies, patients with benign prostatic hyperplasia and patients with urinary dysfunction (International Prostate Symptom Score $\geq 8$ points, prostate volume $\geq 20 \mathrm{~mL}$, maximum urinary flow rate $<15 \mathrm{~mL} / \mathrm{sec}$ [with a minimum urine volume $\geq 130 \mathrm{~mL}$ ], and postvoid residual volume $<100 \mathrm{~mL}$ ). These conditions might have imitated symptoms observed in $\mathrm{OAB}$, so such patients were left out of the study. Healthy volunteers were selected from the hospital staff and had no illnesses, urological or otherwise. The study was acknowledged by the Gaziosmanpasa University local ethics committee (15-KAEK-126).

During the initial visit, patients were asked to complete the overactive bladder-validated 8 (OAB-V8) questionnaire, the International Consultation on Incontinence Questionnaire-Short Form (ICIQ-SF), and the Beck Depression Scale (BDS). The subjects were asked to share information regarding age, weight, height, abnormal lower urinary tract symptoms like difficulty and/or pain resulting from urination, as well as previous pelvic radiotherapy, a feeling of failure in draining the bladder, suprapubic pain, and blood in the urine. Statistical analyses and correlations among the OAB-V8, ICIQ-SF, and BDS scores and patient age were evaluated.

The 202 patients were analyzed within 2 groups: those treated with antidepressants due to disorders such as anxiety disorders, depression, and headache, for at least 3 months $(n=112)$ and a control group with no history of antidepressant usage $(n=90)$. Furthermore, each group, patients with OAB symptoms (OAB-V8 score $\geq 8)$ and those who had not had OAB symptoms $(\mathrm{OAB}-\mathrm{V} 8$ score $<8)$ were also studied in 2 different groups. A comparison of $\mathrm{OAB}$ prevalence with various antidepressant types was performed.

The OAB-V8 advanced questionnaire, which was created to help patients and medical professionals describe OAB symptoms, was used for OAB screenings. It is an assessment form comprised of 8 questions that are scored on a 0 - to 5-point scale (40 points maximum). It is approved for the Turkish population by Tarcan et al. [13]. The ICIQ-SF, which measures the impact of UI on quality of life (QoL), was also used. This form consists of 6 questions, and the evaluation is based on a 21-point scale. In order to define OAB symptoms in Turkish patients, Cetinel et al. [14] published a translated and reconfirmed ICIQ-SF. The BDS consists of 21 questions scored from $0-3$, in a self-report format developed by Beck et al. [15], and was designed to assess the severity of depression symptoms. 
Table 1. Participant characteristics

\begin{tabular}{lccc}
\hline Variable & Healthy control group participants $(\mathrm{n}=90)$ & Antidepressant users $(\mathrm{n}=112)$ & P-value \\
\hline Age $(\mathrm{yr})$ & $37 \pm 9$ & $41.4 \pm 13$ & 0.564 \\
Body mass index $\left(\mathrm{kg} / \mathrm{m}^{2}\right)$ & $24 \pm 5$ & $25 \pm 5$ & 0.786 \\
BDS scores & $8(0-37)$ & $13(0-55)$ & $<0.001^{*}$ \\
OAB-V8 scores & $2.5(0-25)$ & $7.5(1-32)$ & $<0.001^{*}$ \\
ICIQ-SF scores & $0(0-15)$ & $1(0-18)$ & $0.001^{*}$
\end{tabular}

Values are presented as mean \pm standard deviation or median (range).

BDS, Beck Depression Inventory; OAB-V8, overactive bladder-validated 8; ICIQ-SF, International Consultation on Incontinence QuestionnaireShort Form.

${ }^{*} \mathrm{P}<0.05$, statistically significant difference.

Table 2. Incidence of overactive bladder in healthy control group participants versus antidepressant users

\begin{tabular}{lccc}
\hline OAB-V8 & Healthy control group participants $(\mathrm{n}=90)$ & Antidepressant users & P-value \\
\hline$<8$ & $77(85.6)$ & $55(49.1)$ & $<0.001^{*}$ \\
$\geq 8$ & $13(14.4)$ & $57(50.9)$ & \\
\hline
\end{tabular}

Values are presented as number (\%).

$\mathrm{OAB}-\mathrm{V} 8$, overactive bladder-validated 8.

${ }^{*} \mathrm{P}<0.05$, statistically significant difference.

\section{Statistical Analysis}

Numerical variables are expressed as means \pm standard deviation or as medians with the interquartile range, and were evaluated as sought fit with Student t-tests, the Mann-Whitney Utest or the Kruskal-Wallis test. We used a chi-square test to calculate the percentages of the nonnumeric variables. Correlations among the OAB-V8, ICIQ-SF, BDS scores, and patient age were examined using the Spearman correlation analysis. Logistic regression analyses were performed to determine the association of the presence of $\mathrm{OAB}$, other risk factors, and antidepressant usage. We used SPSS ver. 15.0 (SPSS Inc., Chicago, IL, USA) for statistical analyses, and the P-values which are under 0.05 qualified as significant.

\section{RESULTS}

The average age of the participants was $39 \pm 12$ years. Sociodemographic information is reported in Table 1 . The sociodemographic properties were similar for both groups $(\mathrm{OAB}-\mathrm{V} 8 \geq 8$, $\mathrm{OAB}-\mathrm{V} 8<8$ ). The ICIQ-SF, OAB-V8, and BDS scores of antidepressant users were statistically higher than that of the control subjects $(\mathrm{P}<0.001, \mathrm{P}<0.001$, and $\mathrm{P}=0.001$, respectively). The comparison between the 2 groups showed that the frequency of $\mathrm{OAB}$ was significantly higher in the antidepressant users $(50.9 \%$ vs. $14.4 \%, \mathrm{P}<0.001)$ (Table 2$)$. The chi-square test
Table 3. Incidence of overactive bladder in patients, according to antidepressant type

\begin{tabular}{lccc}
\hline Variable & OAB-V8 $<8$ & OAB-V8 $\geq 8$ & P-value \\
\hline Escitalopram $(\mathrm{n}=32)$ & $13(40.6)$ & $19(59.4)$ & $0.046^{*}$ \\
Sertraline $(\mathrm{n}=25)$ & $18(72.0)$ & $7(28.0)$ & \\
Fluoxetine $(\mathrm{n}=15)$ & $9(60.0)$ & $6(40.0)$ & \\
Paroxetine $(\mathrm{n}=18)$ & $8(44.4)$ & $10(55.6)$ & \\
Venlafaxine $(\mathrm{n}=22)$ & $7(31.8)$ & $15(68.2)$ & \\
\hline
\end{tabular}

Values are presented as number (\%). Chi-square test was used for statistical analysis.

OAB-V8; overactive bladder-validated 8.

${ }^{*} \mathrm{P}<0.05$, statistically significant difference.

showed that, among the antidepressant user group, the ones who had been using venlafaxine has the highest prevalence of $\mathrm{OAB}(68.2 \%)$, while the lowest prevalence was found in patients using sertraline (28.0\%; Table 3). Moreover, the difference between the antidepressant groups was statistically significant $(\mathrm{P}=0.046)$. To understand the reason for the statistical significance, each antidepressant was removed one by one and then the statistical analysis (chi-square test) was performed again each time. Statistical significance disappeared only after sertraline was removed $(\mathrm{P}=0.346)$. These results suggested that sertraline has the lowest prevalence of $\mathrm{OAB}$.

There was a positive correlation between the ICIQ-SF scores, 
Table 4. Correlation between variables

\begin{tabular}{lccccc}
\hline Variable & Presence of OAB & Use of antidepressants & Age & OAB-V8 scores & BDS scores \\
\hline Presence of OAB & 1 & $0.361^{* *}$ & 0.145 & $0.835^{* *}$ & $0.197^{* *}$ \\
Use of antidepressants & - & 1 & $0.149^{*}$ & 1 & $0.436^{* *}$ \\
Age & - & - & - & $0.149^{*}$ & $0.260^{* *}$ \\
OAB-V8 scores & - & - & - & 1 & $0.265^{* *}$ \\
BDS scores & - & - & - & 1 \\
\hline
\end{tabular}

OAB, overactive bladder; BDS, Beck Depression Inventory; OAB-V8, overactive bladder-validated 8.

${ }^{*} \mathrm{P}<0.05,{ }^{* *} \mathrm{P}<0.01$, statistically significant difference.

Table 5. Factors affecting the presence of overactive bladder: results of the univariate and multivariate logistic regression analyses

\begin{tabular}{|c|c|c|c|c|c|c|}
\hline \multirow{2}{*}{ Factor } & \multicolumn{3}{|c|}{ Univariate analysis } & \multicolumn{3}{|c|}{ Multivariate analysis } \\
\hline & OR & $95 \% \mathrm{CI}$ & P-value & OR & $95 \% \mathrm{CI}$ & P-value \\
\hline Use of antidepressants & 6.000 & $2.792-12.895$ & $<0.001$ & 4.723 & $2.140-10.421$ & $<0.001^{* *}$ \\
\hline Age & 1.035 & $1.010-1.061$ & 0.006 & 1.025 & $0.999-1.052$ & 0.061 \\
\hline BDS score & 1.037 & $1.011-1.064$ & 0.005 & 1.023 & $0.995-1.051$ & 0.109 \\
\hline
\end{tabular}

BDS, Beck Depression Inventory; CI, confidence interval; OR, odds ratio.

${ }^{* *} \mathrm{P}<0.01$, statistically significant difference.

BDS scores, and patient age with the OAB-V8 scores $\left(r=0.260^{* *}\right.$, $\mathrm{r}=0.268^{* *}$, and $\mathrm{r}=0.212^{* *}$, respectively). Patient age positively correlated with the ICIQ-SF scores $\left(\mathrm{r}=0.354^{* *}\right)$. Furthermore, the presence of OAB positively correlated with the ICIQ-SF scores, BDS scores, and the use of antidepressants $\left(\mathrm{r}=0.330^{* *}\right.$, $\mathrm{r}=0.197^{* *}$, and $\mathrm{r}=0.361^{* *}$, respectively). The use of antidepressants positively correlated with the OAB-V8 scores $\left(\mathrm{r}=0.436^{* *}\right.$, ${ }^{* *} \mathrm{P}<0.01$ ) (Table 4).

As shown in Table 5, the results from the univariate logistic regression analyses showed a significant relationship among the presence of $\mathrm{OAB}$, the use of antidepressants, the BDS scores, and patient age. Additionally, the multivariate logistic regression analyses showed that the relationship between the presence of $\mathrm{OAB}$ and the usage of antidepressants was statistically significant, but patient age and BDS scores were not.

\section{DISCUSSION}

Research has led us to conclude that our study is the first prospective study to evaluate $\mathrm{OAB}$ in male $\mathrm{AD}$ users, and the first to assess the relationship between $\mathrm{OAB}$ and the use of various antidepressants in male patients. All score results (i.e., the BDS, $\mathrm{OAB}$ [and OAB-V8], and ICIQ-SF) were higher for antidepressant users than those in the control group. Our study showed that $\mathrm{OAB}$ was most prevalent in patients using venlafaxine and least prevalent in those using sertraline.

In the literature, several studies have shown that some antidepressants may cause UI. Asplund et al. [10] reported that SSRI users are twice as likely to contract UI than patients not using SSRIs. Similarly, some authors point out that UI is related to antidepressant drug usage, and taking SSRIs is also associated with a higher risk of developing UI [11]. Duloxetine is an antidepressant that functions via both serotonin and norepinephrine reuptake inhibition; it also reduces the frequency of incontinence episodes and decreases leakage volume. Thus, it is recommended for females with management of stress stemming from incontinence [16]. TCAs, such as amitriptyline and imipramine, can be prescribed for anticholinergic treatment-resistant patients, particularly when combined with antimuscarinic agents. Imipramine users reported more anticholinergic effects than SSRIs (dry mouth, constipation, and urinary retention), as well as a higher incidence of headache, dizziness, and vasodilation. This adverse effect may be due to the anticholinergic effects of TCAs [17]. Additionally, some antidepressants can cause UI and an increased number of OAB symptoms [11,12,16,17]. Our study showed that the BDS, OAB-V8, and ICIQ-SF scores in AD users were higher than healthy subjects. Furthermore, regression analyses showed more serious $\mathrm{OAB}$ symptoms and more cases of UI in patients using antidepressants than in those who did not. These findings indicate that using antidepressants might in- 
crease UI susceptibility and the amount of OAB symptoms.

The frequency of $\mathrm{OAB}$ cases in the United States is estimated to be $16 \%$ in males and $17 \%$ in females, but the severity and frequency of symptoms is greater in females. These results may be due to anatomical, physiological, and psychological differences between the sexes $[2,3]$. Prior associations between the use of SSRIs and nocturia and the risk of UI have been reported $[10,11]$. SSRI antidepressants might increase the risk of lower urinary tract symptoms [18], as related pathways are likely to increase cholinergic neuromuscular transmission in the detrusor muscle and disrupt autonomic function $[19,20]$. Some research shows that the inhibition of 5-hydroxytryptamine (5HT) and norepinephrine reuptake plays a crucial role in the regulation of lower urinary tract function [21]. The SSRI users had a higher rate of nocturia and UI in different studies $[10,11]$. In another study, after multivariate adjustment, antidepressants were shown to be positively associated with nocturia in males [22]. Similar to other studies, the present study showed that $\mathrm{OAB}$ was more prevalent in antidepressant users (50.9\%) than in the healthy subjects (14.4\%).

A previous study reported that some patients who were on an SSRI experienced an increase in urinary frequency, nocturia, and urgency [23], unlike individuals using duloxetine, which inhibited both the serotonin and noradrenaline uptake and decreased the UI rate $[24,25]$. This contrary result might be the reflection of the variation in the mechanism of certain ADs (blockage of serotonine and dopamine reuptake) [10]. Cheng and de Groat [26] showed that when endogenous 5-HT activates $5-\mathrm{HT}_{1 \mathrm{~A}}$ receptors, it causes a decrease in the threshold for the initiation of reflex micturation and encourages micturation by extending the external urethral sphincter relaxation time. Venlafaxine, which is also a noradrenaline reuptake inhibitor, has been linked with the induction of UI. Patient urinary symptoms improved when they refrained from taking venlafaxine and started using sertraline. In these circumstances, the development of UI in those patients using venlafaxine, but not sertraline, may imply that plays a role in the inhibition of norepinephrine reuptake, which results in the increase in the extracellular levels of the drug by activating multiple adrenergic receptor subtypes [27]. Stimulation of serotonin receptors with cisapride, a serotonin receptor agonist, increases the yield and frequency of micturition. Some reports showed that in an isolated human detrusor muscle, serotonin might potentiate cholinergic neuromuscular transmission indirectly by activating serotonin receptors [28]. Sertraline allows a stronger inhibitory impact of dopamine reuptake than other SSRIs, and this factor may be associated with a higher risk of UI contraction in antidepressant users $[11,29]$. Several studies showed that sertraline increases the frequency of UI cases; however, other studies have reported that antidepressant-induced UI does not re-emerge after patients switch to sertraline [11,27]. In contrast with these data, $\mathrm{OAB}$ was most prevalent in patients who were prescribed venlafaxine (68.2\%) and the lowest in patients using sertraline (28.0\%). These conflicting results may result from antidepressants that have distinct characteristics, or that exert various effects on different receptors.

Several studies reported a positive association of $O A B$ in subjects with depressive symptoms and anxiety [30]. OAB symptoms can be disturbing, and along with the need for healthcare, may also cause depression and anxiety. In the literature, depression rates were reportedly higher in subjects with $\mathrm{OAB}$, and vice versa [31]. Also, the $\mathrm{OAB}$ frequency increases with age [32]. Even though our study showed that there was a positive correlation between ICIQ-SF scores, BDS scores and patient age with the OAB-V8 scores, the multivariate logistic regression analyses showed that $\mathrm{AD}$ usage is the main factor that affects $\mathrm{OAB}$. In regards to our study, evidence indicates the existence of a relationship between the severity of OAB symptoms and $\mathrm{AD}$ usage.

In conclusion, the present study showed that males taking certain $\mathrm{ADs}$ (escitalopram, sertraline, fluoxetine, paroxetine, venlafaxine) experience an increased incidence of $\mathrm{OAB}$ and more severity symptoms. Each antidepressant (especially SSRIs and SNRIs) has a different pharmacological profile, which may offer an explanation for contradictory previous studies. We suggest that male patients who are prescribed ADs should be carefully observed for $\mathrm{OAB}$ related symptoms.

\section{REFERENCES}

1. Abrams P, Andersson KE, Birder L, Brubaker L, Cardozo L, Chapple $\mathrm{C}$, et al. Fourth International Consultation on Incontinence Recommendations of the International Scientific Committee: Evaluation and treatment of urinary incontinence, pelvic organ prolapse, and fecal incontinence. Neurourol Urodyn 2010;29:213-40.

2. Stewart WF, Van Rooyen JB, Cundiff GW, Abrams P, Herzog AR, Corey R, et al. Prevalence and burden of overactive bladder in the United States. World J Urol 2003;20:327-36.

3. Coyne KS, Sexton CC, Vats V, Thompson C, Kopp ZS, Milsom I. National community prevalence of overactive bladder in the Unit- 
ed States stratified by sex and age. Urology 2011;77:1081-7.

4. Chapple C. Chapter 2: Pathophysiology of neurogenic detrusor overactivity and the symptom complex of "overactive bladder". Neurourol Urodyn 2014;33 Suppl 3:S6-13.

5. Geddes JR, Carney SM, Davies C, Furukawa TA, Kupfer DJ, Frank $\mathrm{E}$, et al. Relapse prevention with antidepressant drug treatment in depressive disorders: a systematic review. Lancet 2003;361:653-61.

6. den Boer JA, Westenberg HG, De Leeuw AS, van Vliet IM. Biological dissection of anxiety disorders: the clinical role of selective serotonin reuptake inhibitors with particular reference to fluvoxamine. Int Clin Psychopharmacol 1995;9 Suppl 4:47-52.

7. Lindsley CW. The top prescription drugs of 2011 in the United States: antipsychotics and antidepressants once again lead CNS therapeutics. ACS Chem Neurosci 2012;3:630-1.

8. Kyle CJ, Petersen HE, Overø KF. Comparison of the tolerability and efficacy of citalopram and amitriptyline in elderly depressed patients treated in general practice. Depress Anxiety 1998;8:147-53.

9. Hay-Smith J, Herbison P, Ellis G, Morris A. Which anticholinergic drug for overactive bladder symptoms in adults. Cochrane Database Syst Rev 2005;(3):CD005429.

10. Asplund R, Johansson S, Henriksson S, Isacsson G. Nocturia, depression and antidepressant medication. BJU Int 2005;95:820-3.

11. Movig KL, Leufkens HG, Belitser SV, Lenderink AW, Egberts AC. Selective serotonin reuptake inhibitor-induced urinary incontinence. Pharmacoepidemiol Drug Saf 2002;11:271-9.

12. Albayrak S, Solmaz V, Gencden Y, Firat F, Oran Demir M, Aksoy $\mathrm{D}$, et al. Assessment of overactive bladder in women antidepressant users. Int Urol Nephrol 2015;47:1479-84.

13. Tarcan T, Mangır N, Özgür MÖ, Akbal C. OAB-V8 Aşırı aktif mesane sorgulama formu validasyon çalışması. Üroloji Bülteni 2012; 21:113-6.

14. Cetinel B, Ozkan B, Can G. The validation study of ICIQ-SF Turkish version. Turk J Urol 2004;30:332-8.

15. Beck AT, Ward CH, Mendelson M, Mock J, Erbaugh J. An inventory for measuring depression. Arch Gen Psychiatry 1961;4:561-71.

16. Guay DR. Duloxetine for management of stress urinary incontinence. Am J Geriatr Pharmacother 2005;3:25-38.

17. Chancellor M, Boone T. Anticholinergics for overactive bladder therapy: central nervous system effects. CNS Neurosci Ther 2012; 18:167-74.

18. Wuerstle MC, Van Den Eeden SK, Poon KT, Quinn VP, Hollingsworth JM, Loo RK, et al. Contribution of common medications to lower urinary tract symptoms in men. Arch Intern Med 2011;171: 1680-2.

19. Tonini M, Candura SM. 5-HT4 receptor agonists and bladder disorders. Trends Pharmacol Sci 1996;17:314-6.
20. Bär KJ, Greiner W, Jochum T, Friedrich M, Wagner G, Sauer H. The influence of major depression and its treatment on heart rate variability and pupillary light reflex parameters. J Affect Disord 2004;82:245-52.

21. Andersson KE. Treatment of the overactive bladder: possible central nervous system drug targets. Urology 2002;59(5 Suppl 1):18-24.

22. Tikkinen KA, Auvinen A, Johnson TM 2nd, Weiss JP, Keränen T, Tiitinen A, et al. A systematic evaluation of factors associated with nocturia--the population-based FINNO study. Am J Epidemiol 2009;170:361-8.

23. Votolato NA, Stern S, Caputo RM. Serotonergic antidepressants and urinary incontinence. Int Urogynecol J Pelvic Floor Dysfunct 2000;11:386-8.

24. van Kerrebroeck P, Abrams P, Lange R, Slack M, Wyndaele JJ, Yalcin I, et al. Duloxetine versus placebo in the treatment of European and Canadian women with stress urinary incontinence. BJOG 2004;111:249-57.

25. Viktrup L, Bump RC. Pharmacological agents used for the treatment of stress urinary incontinence in women. Curr Med Res Opin 2003;19:485-90.

26. Cheng CL, de Groat WC. Role of 5-HT1A receptors in control of lower urinary tract function in anesthetized rats. Am J Physiol Renal Physiol 2010;298:F771-8.

27. Polimeni G, Salvo F, Cutroneo P, Nati G, Russo A, Giustini ES, et al. Venlafaxine-induced urinary incontinence resolved after switching to sertraline. Clin Neuropharmacol 2005;28:247-8.

28. Tonini M, Messori E, Franceschetti GP, Rizzi CA, Castoldi AF, Coccini T, et al. Characterization of the 5-HT receptor potentiating neuromuscular cholinergic transmission in strips of human isolated detrusor muscle. Br J Pharmacol 1994;113:1-2.

29. Tatsumi M, Groshan K, Blakely RD, Richelson E. Pharmacological profile of antidepressants and related compounds at human monoamine transporters. Eur J Pharmacol 1997;340:249-58.

30. Perry S, McGrother CW, Turner K; Leicestershire MRC Incontinence Study Group. An investigation of the relationship between anxiety and depression and urge incontinence in women: development of a psychological model. Br J Health Psychol 2006;11(Pt 3):463-82.

31. Milsom I, Kaplan SA, Coyne KS, Sexton CC, Kopp ZS. Effect of bothersome overactive bladder symptoms on health-related quality of life, anxiety, depression, and treatment seeking in the United States: results from EpiLUTS. Urology 2012;80:90-6.

32. Selvaraj J, Kekre AN, Varghese L, Jacob KS. Symptoms, prevalence, and risk factors of overactive bladder in women in south India. Int J Gynaecol Obstet 2015;129:274-5. 